\title{
Severe Hypokalemia ECG Changes Mimicking Those of Acute Coronary Syndrome (ACS) in Patient with Underlying Ischaemic Heart Disease: A Case Review
}

\author{
C. Sethuraman, S. F. Mohd, S. Govindaraju, W. J. Tiau, N. D. Mohamad Farouk, H. H. Che Hassan \\ Department of Medicine, Universiti Kebangsaan Malaysia, Kuala Lumpur, Malaysia \\ Email: hamathamdi@gmail.com
}

How to cite this paper: Sethuraman, C., Mohd, S.F., Govindaraju, S., Tiau, W.J., Farouk, N.D.M. and Hassan, H.H.C. (2020) Severe Hypokalemia ECG Changes Mimicking Those of Acute Coronary Syndrome (ACS) in Patient with Underlying Ischaemic Heart Disease: A Case Review. Open Journal of Emergency Medicine, 8, 53-58.

https://doi.org/10.4236/ojem.2020.82006

Received: March 31, 2020

Accepted: May 11, 2020

Published: May 14, 2020

Copyright $\odot 2020$ by author(s) and Scientific Research Publishing Inc. This work is licensed under the Creative Commons Attribution International License (CC BY 4.0).

http://creativecommons.org/licenses/by/4.0/

\section{(c) (i) Open Access}

\begin{abstract}
Background: Hypokalemia is seen on regular basis in medical emergency. The definition of hypokalemia is serum potassium level below $3.5 \mathrm{mmol} / \mathrm{L}$, meanwhile severe hypokalemia is serum potassium level below $2.5 \mathrm{mmol} / \mathrm{L}$ [1]. Patient with hypokalemia can present with wide range of presentation including musculoskeletal complaints from numbness to acute paralysis. Severe hypokalemia has tendency to progress to intestinal paralysis and respiratory failure. In some cases of hypokalemia, cardiovascular system can also be affected causing cardiac arrhythmias and heart failure [2]. Aim: This case report is to highlight that severe hypokalaemia can present with ECG changes mimicking acute coronary syndrome (ACS) which was fully resolved with correction of potassium level. Methods: We report a case of 84 years old Chinese man with underlying triple vessel disease presented with generalised body weakness for 2 days. ECG on arrival noted changes suggestive of ACS with ST segment depression in lead V4-V6 with first degree heart block, however patient had no ischemic symptoms and the potassium level was severe low at $1.6 \mathrm{mmol} / \mathrm{L}(3.5-5.1 \mathrm{mmol} / \mathrm{L})$. He was correctly not treated for ACS. Outcomes: Repeated ECG post fast intravenous potassium correction noted complete resolution of the ST segment depression and first degree heart block. Patient discharged well from hospital four days later with potassium level of $3.8 \mathrm{mmol} / \mathrm{L}$. Conclusions: Severe hypokalemia with asymptomatic ECG of ACS changes can safely be treated as a single entity clinical emergency with good resolution and no complication after normalizing potassium level.
\end{abstract}

\section{Keywords}

Hypokalemia, ECG Changes, Acute Coronary Syndrome (ACS), Ischaemic 


\section{Case Report}

This is a case of 84 years old Chinese man with underlying diabetes mellitus, hypertension, dyslipidaemia, recurrent stroke, prostate carcinoma on conservative management, recent pneumonia and ischaemia heart disease (IHD). CTA Coronary angiography done on May 2019 revealed 3 vessel disease with possible complete total occlusion of OM1. Patient has refused for coronary angiogram and opted for conservative management.

Patient was previously admitted on early November 2019 at a private hospital for pneumonia and was treated with IV antibiotics. Patient subsequently had diarrhea for few days and poor oral intake after discharge. He presented to us a few weeks later at the end of November 2019 with generalized body weakness for two days. He had vomited once prior to admission, however his diarrhea had resolved. Patient denied fever, chest pain, shortness of breath, upper respiratory or urinary tract infection symptoms.

Upon arrival in emergency department, patient was alert and conscious with stable vital signs. Blood pressure of $114 / 65 \mathrm{mmHg}$, pulse rate was 69 beats per minute, temperature was $36.7^{\circ} \mathrm{C}$ and oxygen saturation was $96 \%$ on room air. Lungs examination noted bilateral crepitation which is consistent with underlying old pneumonia. Cardiovascular examination was unremarkable with no murmur noted and per abdomen examination was also unremarkable with soft abdomen.

The initial blood investigation of an arrival revealed Hemoglobin level of 12.9 $(13.0-17.0 \mathrm{~g} / \mathrm{dL})$, total white cell count of $7.0[4.0-10.0 \times 10(9)]$, Platelet count of 182 [150 - $410 \times 10(9)$ ], sodium level of $128(136-145 \mathrm{mmol} / \mathrm{L})$, potassium level of $1.6(3.5-5.1 \mathrm{mmol} / \mathrm{L})$, magnesium level of $0.81(0.66-1.07 \mathrm{mmol} / \mathrm{L})$, phosphate level of $0.97(0.74-1.52 \mathrm{mmol} / \mathrm{L})$, corrected calcium level of 2.16 $(2.14-2.58 \mathrm{mmol} / \mathrm{L})$, urea level of $3.0(3.2-7.4 \mathrm{mmol} / \mathrm{L})$, creatinine level of 132 (136 - $145 \mathrm{umol} / \mathrm{L}), \mathrm{pH}$ of 7.550 (7.35 - 7.45), bicarbonate level of 37.0 (21.0 $28.0 \mathrm{mmol} / \mathrm{L})$, Lactate level of $1.4(0.5-1.6 \mathrm{mmol} / \mathrm{L})$, CRP level of $5.73(<0.5$ $\mathrm{mg} / \mathrm{dL}$ ). The cardiac enzyme was not taken due to clear evidence of hypokalemia which was the culprit of ECG changes and further supported by lack of ischemic symptoms during presentation.

Initial ECG noted atrial fibrilation with ventricular rate about 75 beats per minute, ST Depression in leads V4-V6 and first degree AV block as per Figure 1. Chest radiograph was unremarkable besides some chronic lung disease changes as per Figure 2.

Patient was admitted to ward with initial impression of severe hypokalaemia and metabolic alkolosis secondary to gastrointestinal loss and poor oral intake. Patient was given intravenous fast correction of potassium chloride. Repeated electrocardiogram post intravenous fast potassium correction noted 
sinus rhythm with ventricular rate about 70 beats per minute, resolved ST depression at lead V4-V6 with no evolving changes (Figure 3). Repeated potassium level after complete ECG resolution was $2.3 \mathrm{mmol} / \mathrm{L}$ (3.5 - $5.1 \mathrm{mmol} / \mathrm{L})$.

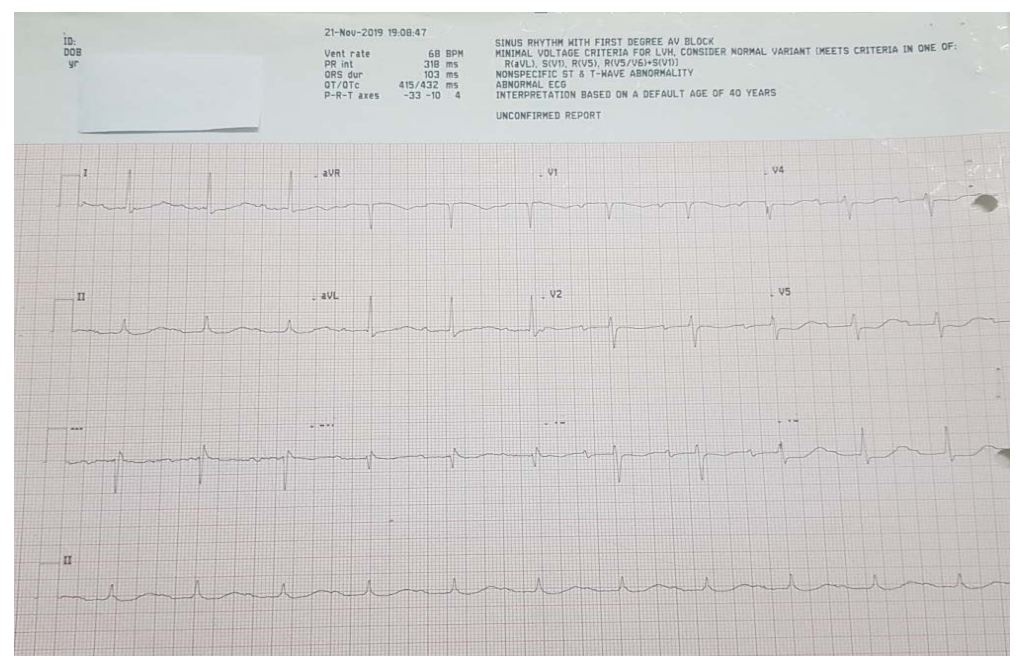

Figure 1. Electrocardiogram on arrival.

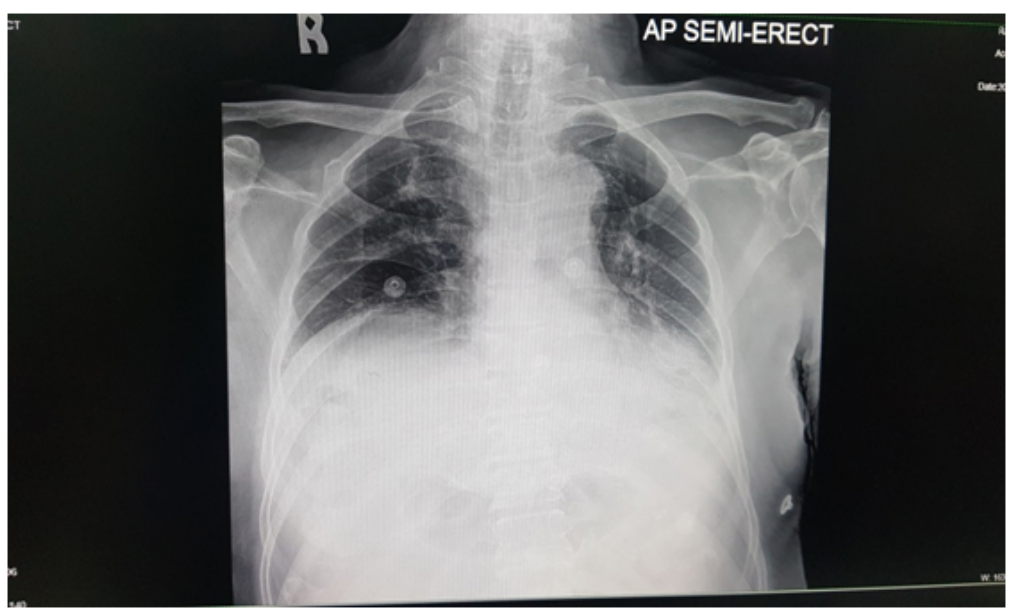

Figure 2. Chest radiograph on admission.

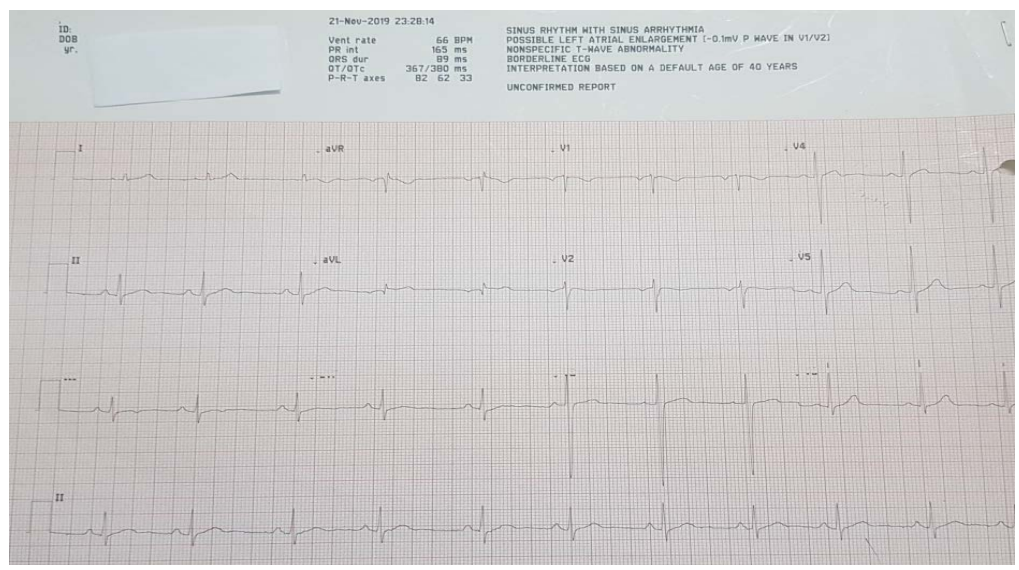

Figure 3. Electrocardiogram post intravenous fast potassium correction. 
Patient was given intravenous potassium correction and oral potassium supplement accordingly with serum potassium monitoring in ward. Patient became more active in ward and appetite was improved. Patient was subsequently discharged 4 days after admission with potassium level of $3.8 \mathrm{mmol} / \mathrm{L}$ (3.5 - 5.1 $\mathrm{mmol} / \mathrm{L})$. Patient was reviewed 1 week later at clinic and his repeated potassium level was $3.0 \mathrm{mmol} / \mathrm{L}$ (3.5 - $5.1 \mathrm{mmol} / \mathrm{L})$. Patient's electrocardiogram images are as follows:

\section{Discussion}

Hypokalemia can present with varying ECG changes. A study was conducted by Grischa Marti et al. showed that $69 \%$ patients noted to have ECG changes due to hypokalemia. The commonest ECG changes associated with hypokalemia were presence of $U$ wave which counted for $24 \%$ patients, while $21 \%$ patients had ST segment depression and multiple ventricular extrasystole occurance [3].

Intracellular and extracellular potassium concentration gives rise to resting transmembrane potential difference. Cellular hyperpolarity caused by hypokalemia raises resting potential and subsequently accelerates depolarization. This is followed by raise in automaticity and excitability. This will cause multiple ST changes in the ECG. Hypokalemia also prolongs the action potential and causes raised QT dispersion [4].

There is another possibility for ECG changes in our patient which is the vasoconstriction effect of hypokalemia. A drop in potassium level is associated with vasoconstriction [5]. Our patient have underlying 3 vessel disease, hypokalemia may induced myocardial vasontriction resulting in relative cardiac muscle hypoxia which possibly give rise to ACS like ECG of ST depression. Intravenous fast potassium correction may incur vasodilation effect besides slowing down cardiac muscle depolarization and excitability which results in resolution of ST segment depression on ECG.

A case report by Sokolovic S et al. has showed association between hypokalaemia and non-obstructive coronary artery myocardial obstruction. A young woman was admitted for non ST elevation myocardial infarction following a chest pain. The coronary angiogram was done and the finding was slow flow of coronary arteries without significant obstruction. The cause of the patient presentation and ECG findings was attributed to low serum potassium level of 3.2 $\mathrm{mmol} / \mathrm{L}(3.5$ - $5.1 \mathrm{mmol} / \mathrm{L})[6]$.

A study was conducted by NurRahmah Musa et al. to assess the ECG improvement post potassium correction in patients with hypokalaemia. The most prevalent ECG changes in this study were long QT interval and prominent U wave. The study concluded that improvement in ECG can be seen post potassium correction even before the serum potassium achieves normal level [7]. Our patient in this case report has complete resolution of ECG at a very low potassium level of $2.3 \mathrm{mmol} / \mathrm{L}$ (3.5 - $5.1 \mathrm{mmol} / \mathrm{L})$.

A case report by Daniel Bogdonavpetrov et al. concluded that hypokalemia 
have tendency to mimic myocardial infarction and differentiating the cause of ECG changes can be challenging if patient present with chest discomfort [8]. According to an article in international journal of medicine in 2018, hypokalemia not commonly present with deep and prominent ST depression. CT coronary angiogram and transthoracic echocardiogram was performed for a patient presented with hypokalemia and ST depression to rule out possible concomitant IHD, however the findings turned out to be normal and the ST segment depression was resolved after potassium correction [9].

Patient with underlying IHD presenting with hypokalemia and ACS like ECG needs precise assessment to avoid the trick of underestimating ACS as hypokalemia or overestimating hypokalemia as ACS. Patients with no history of previous or current IHD presenting with hypokalemia and ACS like ECG needs further screening for possible underlying IHD.

\section{Conclusion}

As a conclusion, severe hypokalemia can present with variety of ECG changes including acute ischemic changes and can be solved medically and correctly with rapid potassium correction without much of other medical complications.

\section{Acknowledgements}

Informed consent was obtained from the patient to report this case.

\section{Conflicts of Interest}

The authors declare no conflicts of interest regarding the publication of this paper.

\section{References}

[1] Wang, X.Q., et al. (2018) Electrocardiograpic Manifestations in Severe Hypokalemia. Journal of International Medical Research, 1-7. https://doi.org/10.1177/0300060518811058

[2] Kardalas, E., et al. (2018) Hypokaalemia: A Clinical Update. Endocrine Connections, 7, R135-R146. https://doi.org/10.1530/EC-18-0109

[3] Marti, G., et al. (2014) Etiology and Symptoms of Severe Hypokalemia in Emergency Department Patients. European journal of Emergency Medicine, 21, 46-51.

[4] Macdonald, J.E., et al. (2004) What Is the Optimal Serum Potassium Level in Cardiovascular Patients? Journal of the American College of Cardiology, 43. https://doi.org/10.1016/j.jacc.2003.06.021

[5] Sekiyama, H., et al. (2013) Transient Decrease in Serum Potassium Level during Ischaemic Attack of Acute Coronary Syndrome: Paradoxical Contribution of Plasma Glucose Level and Glycohemoglobin. Cardiovascular Diabetology, 12, 4. https://doi.org/10.1186/1475-2840-12-4

[6] Sokolovic, S., et al. (2019) Hypokalaemia Associated with Non-Obstructive Coronary Arteries Myocardial Infarction. Res., 2, 1016.

[7] Musa, N.R., et al. (2019) Electrocardiogram Pattern Pre and Post Potassium Correc- 
tion in Hypokalaemia. International Journal of Medical Reviews and Case Reports, 3, 711-716.

[8] Petrov, D.V., et al. (2012) Severe Hypokalemia Masquerading Myocardial Infarction. Cardiol Res, 3, 236-238.

[9] (2018) An International Journal of Medicine, 581-582. 